The Review of Finance and Banking

print ISSN 2067-2713, online ISSN 2067-3825

Volume 12, Issue 2, Year 2020

http://dx.doi.org/10.24818/rfb.20.12.02.03, Pages 137-154

\title{
NETWORK RISK IN THE EUROPEAN SOVEREIGN CDS MARKET
}

\author{
ZORNITSA TODOROVA
}

\begin{abstract}
This paper applies novel tools from spatial econometrics to measure, quantify and predict sovereign CDS spreads. Network risk is modelled by making each sovereign's CDS spread a function of the CDS spreads of its "neighbors" in the financial network. The main findings of the paper are: (1) the network model improves forecasting accuracy by 15 $\%$ to $20 \%$; (2) exogenous financial shocks propagate in the network of sovereigns and $40 \%$ to $50 \%$ of the total effect is due to indirect (network) effects. These findings suggest an alternative explanation to the well-known credit spread puzzle. To rationalize the findings the paper develops a simple structural network model of sovereign credit risk with financial cross-holdings and multiple equilibria.
\end{abstract}

\section{INTRODUCTION}

Sovereign credit default spreads (CDS) in the Euro-area feature a time-varying pattern of comovement, which constitutes a major challenge for econometric modelling and forecasting. During the recent European Sovereign Debt Crisis of 2010-2012 spreads have reached levels that cannot be predicted by standard models, which typically model spreads as a persistent mean-reverting process driven by two factors: a local and a global factor. The local factor is determined by fundamentals, whereas the global factor captures risk aversion i.e. proxies for global market conditions. Predicted spreads from these models cannot match the pattern in the data and are, on average, 100 basis points lower than realized values. This empirical evidence suggests a non-linear relationship between a sovereign's theoretical probability of default and observed credit spreads, a phenomenon dubbed as the "credit spread puzzle" (Amato \& Remolona (2003); Chen, Collin-Dufresne, \& Goldstein (2008); Longstaff, Pan, Pedersen, \& Singleton (2011)).

Until recently, the probability of a developed country defaulting on its sovereign debt was considered to be close to zero. However, with the onset of the Global Liqudity and the subsequent European Sovereign Debt Crisis many governments had to step in and save their financial sectors, as a result of which fiscal deficits reached levels unseen since World War II. This led to a revision of credit markets and raised a discussion about the true probability of sovereign default. Credit rating agencies responded with a series of downgrades, notwithstanding developed countries. For example, Germany was the only country in Europe, which retained its AAA rating.

Received by the editors July 19, 2019. Accepted by the editors September 10, 2020.

Keywords: Pnetworks, financial contagion, CDS spreads, spatial autoregressive model.

JEL Classification: D85, E44, G12, G15.

Zornitsa Todorova, PhD, Research Associate, Barclays Investment Bank, Global Research, 5 North Colonnade, Canary Wharf, London E14 4EY, UK. E-mail: zornitsa.todorova@barclays.com.

This paper is in final form and no version of it will be submitted for publication elsewhere. An unpublished version of the paper has been previously circulated as "Systemic Risk and Network Spillovers in the European Sovereign CDS Market: A Spatial Autoregressive Approach", RES Symposium for Junior Researchers, paper ID 262 .

Disclaimer: The opinions expressed in this publication are those of the author and do not reflect the opinions or views of Barclays. This publication was developed while the author was completing her $\mathrm{PhD}$ thesis at Bocconi University, Department of Finance. 
Furthermore, in the aftermaths of the European Sovereign Debt crisis economists, policymakers and the media have raised concerns over the different forms of contagion in the financial system. One common source of anxiety is that given the interconnectedness of the European financial systems, the default of one country would have spillover effects that would result in higher borrowing costs for other sovereigns, and potentially would trigger a series of other defaults.

Addressing the three points outlined above, this paper proposes the alternative explanation that the credit spread puzzle originally evolves from network risk. Building on recent work by Eder \& Keiler (2015) and Blasques et al. (2016), the paper constructs a network risk factor, which captures time-varying financial linkages among European sovereigns. The factor is constructed as a country-speficic weighted average of CDS spreads, where the weighting scheme is determined by financial network connections and the model is estimated in a spatial autoregressive framework (SAR). The new systemic factor reflects important nonlinearities in CDS markets, because it allows that the credit risk of one sovereign depends not only on its own fundamentals, but also on the credit risk of the countries to which it is financially exposed.

The main contribution of the paper is to demonstrate that the network factor has substantial predicitive ability in sovereign CDS markets. In out-of-sample tests, the SAR model is better able to match monthly CDS spreads and leads to $15 \%$ to $20 \%$ improvement in predictive accuracy, measured in the root mean squared error (RMSE) sense. Since network risk is system-inherent and undiversifiable, markets demand a risk premium for holding sovereign credit risk. To corroborate this intuition, the paper shows that the network of financial linkages between sovereigns is an important mechanism for the transmission of exogenous financial shocks. Empirical evidence shows that as much as $50 \%$ of the overall effect of shocks is due to network spillovers.

The results are consistent with a "balance sheet" mechanism of contagion, where spillovers from a severe financial shock occur via direct losses to assets held by creditors. In the presence of asset interdependencies and discontinuities in value multiple equilibrium solutions for organization's values are possible. In this context of multiple equilibria, network contagion emerges because of linkages and the joint determination of asset prices: sovereigns experience losses because investors expect that other connected sovereigns will incur losses as well and this then becomes self-fulfilling.

\section{Related Literature}

This paper contributes to two main strands of literature. First, it is related to the literature studying modeling and forecasting credit spreads in the euro area. The standard specification adopted for sovereign spreads in the Euro Area models them as a persistent process reverting to a time-varying mean explained by two factors: a local country-specific factor, related to fiscal fundamentals, and a global factor, which measures market appetite for risk (Favero, Pagano and von Thadden (2010); Beber, Brandt and Kavajecz (2009); Laubach (2009, 2011); Attinasi, Checherita and Nickel (2010)). While these models are intuitive and simple, many studies find that they actually fail to explain the actual level of credit spreads. This paper proposes to use the information contained in the financial linkages between sovereigns to predict credit spreads. The idea is that the presence of network connections introduces simultaneity in the determination of spreads. A credit event occurring in one country is transmitted to related countries through the network of financial linkages. In this sense, the paper builds on insights from the theoretical literature studying contagion in financial networks ${ }^{1}$.

\footnotetext{
${ }^{1}$ Important contributions in the field include: Allen and Gale (2000); Freixas, Parigi and Rochet (2000); Eisenberg and Noe, (2001); Suzuki (2002); Leitner, Y. (2005); Nier, E., Yang, J., Yorulmazer, T., \& Alenton, A. (2007); Allen, Babus and Carletti (2010); Rogers and Veraart (2013); Elliot, Golub and Jackson (2014); Acemoglu, D., Ozdaglar, A., \& Tahbaz-Salehi (2015); Barucca, P., Bardosia, M., Caccioli, F., D'Errico, M., Visentin, G., Battiston, S., \& Caldarelli, G. (2016); Gai, P., Hadane, A., \& Kapadia, S. (2011).
} 
Second, this paper contributes to the literature on market spillovers ${ }^{2}$.Several approaches has been proposed in the literature so far. Diebold and Yilmaz (2009,2011) measure spillovers by employing variance decomposition of Vector Autoregressive models (VARs). Another approach is the Global Vector Autoregressive model (GVAR) advanced by Peseran, Schuermann and Weiner (2004). An important contribution in this field is Favero (2013), who augments the standard GVAR framework by introducing a global spread, which is a weighted average of the spreads of other countries, where the weights are given by distances in the fiscal fundamentals (debt and deficit) between countries. This paper uses a Spatial Autoregressive model (SAR) to measure spillover effects. The approach been traditionally developed in regional and social sciences (Prucha and Kelejian ((1998), (1999), (2004), (2006), (2010); Anselin and Bera (1998); LeSage and Pace (2009); Arbia ((2006), (2012); Lee (2004) $)^{3}$. SAR models provide a parsimonious and flexible framework, which accommodates for spreads co-movement and network heterogeneity.

This paper contributes to a nascent literature of spatial econometrics in economics and finance ${ }^{4}$. Content wise, this work is closest to Blasques et al. (2016) and Eder and Keiler (2015). The former discusses the statistical properties of a model with time-varying spatial dependence in the context of sovereign credit markets. The article by Eder and Keiler investigates a network determined by asset correlations on the stock market between systemically important institutions and finds that between $10 \%$ to $15 \%$ of the CDS variance can be explained by network connections. The results of this paper complement the findings of Eder and Keiler (2015). The empirical focus here is out-of-sample prediction of sovereign CDS spreads using a SAR model. Furthermore, the paper provides additional insights by developing a theoretical structural model of cross-border lending, whereby providing a micro-foundation for network spillovers in sovereign CDS markets.

\section{Theoretical Framework}

3.1. Model. This section develops a simple input-output model with interbank cross-holdings in the spirit of Eisenberg and Noe (2001), Suzuki (2002) and Elliot, Golub and Jackson (2014). The model unfolds in the following steps.

Step 1: The financial sector collects deposits and equity and invests in primitive assets and bilateral claims.

Consider a financial system composed of $n$ countries making up a set $N=\{1, . ., n\}$. In each country, the financial sector collects deposits $(d)$ and equity $(e)$ and invests these in primitive assets $M=\{1, . ., m\}$. The term "financial sector" is understood here as the collection of all BIS-reporting banks in a given country. To fix ideas, a primitive asset may be thought of as a project that generates net cash flow over time. Let the amount of the primitive asset $k$ of bank $i$ at time $t$ be $\pi_{i k t}$ and $p_{k t}$ be its price, then $\pi_{i k t} p_{k t}$ is the book value of the primitive assets. Financial sectors also lend to foreign governments. Sovereign debt claims $a_{i j t}$ give the amount that the financial sector of country $i$ lends to the general government of country $j$. All magnitudes are expressed in monetary term. The balance sheet of bank $i$ is given by:

$$
d_{i}+e_{i}+a_{1 i}+\cdots+a_{n 1}=a_{i 1}+\cdots+a_{i n}+\sum_{k} \pi_{i k} p_{k}
$$

Aggregating the balance sheets of all the $n$ banks and expressing it in matrix form:

\footnotetext{
${ }^{2}$ Papers studying spillovers from a systemic point of view are Geier, A., Kossmeier, S., \& Pichler, S. (2004); Gande, A., \& Parsley, D. (2005); Battiston, S., Gatti, D., Gallegatti, M., Greenwald, B., \& Stiglitz, J. (2012); Georg, C. (2013); Bonaldi, P., Hortacsu, A., \& Kastl, J. (2014); Glasserman, P., \& Young, H. (2015); Glover, B., \& Richards-Shubik, S. (2016).

${ }^{3}$ Empirical contributions in social and regional sciences include Kim, Phipps and Anselin (2003); Bordignon, Cerniglia, \& Revelli (2003); Bloningen et al. (2007) among others.

${ }^{4}$ For example, Fernandez (2011) develops a spatial version of the capital asset pricing model (CAPM) in finance and Ozdagli and Weber (2016) study how monetary policy shocks transmit through production networks.
} 


$$
d+e+A_{M} \iota_{n}=A^{\prime}{ }_{M} \iota_{n}+\Pi p
$$

where $\iota_{n}$ is column vector of ones, $\Pi$ is $n \times m$ matrix and $A_{M}$ is bilateral cross-border exposure.

Step 2: Exogenous financial shocks realize.

Step 3: Market Valuation.

Following the realization of a shock, valuation of claims and investments is performed and market value obtains. Market value can substantially differ from the book value of assets, because it depends on the assets of other countries in the model, and more precisely, on how much they value their assets. Let $\mathbb{U}: \mathbb{R}^{q} \rightarrow[0,1]$ be a valuation function that is non-decreasing and continuous from above. If $\mathbb{U}^{I B}(V)$ and $\mathbb{U}(V)^{P A}$ are the valuation functions for the crossborder claims and the proprietary assets respectively, then the market value of assets is given by:

$$
V=A^{\prime}{ }_{M} \iota_{n} \mathbb{U}^{C B}(V)+\Pi p \mathbb{U}^{P A}(V)
$$

The intuition behind the definition is that the market value of any asset can be written as the product of its book value multiplied by the valuation function. Thus, the market value of an asset ranges from its face value to zero.

Step 4: Default costs incur.

The model assumes that if the value of an organization $V$ falls below some threshold $V$, then it is said to fail and incurs a failing cost of $\gamma$ proportionate to the price of the proprietary asset and expressed as fraction of cents on the euro. The organization incurs this cost, because it needs to liquidate its asset in order to cover its liabilities. Since debt is given priority over equity in this setting, it can be assumed that organizations are always able to recover the market value of their interbank claims. Such discontinuities could easily be accommodated in the valuation function $\mathbb{U}(V)$ using the following rule:

$$
\begin{gathered}
\text { 1. } \mathbb{U}^{C B}=1 \\
\text { 2. } \mathbb{U}^{P A}=I_{V>\underline{V}}+\left(I_{V \leq \underline{V}}-\gamma I_{V \leq \underline{V}}\right)
\end{gathered}
$$

The discontinuous drop imposes a loss on the organization and so its value becomes:

$$
V=A^{\prime}{ }_{M} \iota_{n}+\Pi p\left(I_{V>\underline{V}}+\left(I_{V \leq \underline{V}}-\gamma I_{V \leq \underline{V}}\right)\right)
$$

Let $\hat{V}$ be a diagonal matrix such that $\hat{V} \iota_{n}=V$. Then, it is possible to express market values as:

$$
\begin{aligned}
V & =\hat{V}^{-1} A^{\prime}{ }_{M} \hat{V} \iota_{n}+\Pi p\left(I_{V>\underline{V}}+\left(I_{V \leq \underline{V}}-\gamma I_{V \leq \underline{V}}\right)\right) \\
& =Z V+\Pi p\left(I_{V>\underline{V}}+\left(I_{V \leq \underline{V}}-\gamma I_{V \leq \underline{V}}\right)\right)
\end{aligned}
$$

where $Z=\hat{V}^{-1} A^{\prime}{ }_{M}$ is a matrix such that each row is divided by the total assets of the lending bank and so its entries are fractions of unity. Define the parameter $\psi \in[0,1)$, which gives the average contribution of cross-border lending to the total value of the organization. This parameter is endogenously determined from the model as it depends on the face value of interbank claims and assets and their market valuations. Finally, introducing $W=\frac{1}{\psi} Z$ the model writes as:

$$
V=\psi W V+\Pi p\left(I_{V>\underline{V}}+\left(I_{V \leq \underline{V}}-\gamma I_{V \leq \underline{V}}\right)\right)
$$

Step 5: Claims are established for the next period.

Step 6: CDS contracts are traded for credit events in the next period. 
3.2. Equilibrium. The equilibrium concept is investigated in the context of a process, which repeats itself over $t=1, \ldots, T$ number of periods. Each period is treated independently and is assumed to unfold the same steps. A solution for the values of organizations in equation (6) is an equilibrium set of values that takes into consideration dependencies between countries. Invoking Tarski's fixed point theorem (Tarski, 1955), it is possible to show that there always exists a solution to the problem in (6), and moreover, that there is a least and a greatest solution. In fact, the set of solutions forms a complete lattice, which follows from the fact that failures are strategic complements.

The presence of discontinuities and equilibrium multiplicity can come from two distinct sources. The first type of discontinuity arises when the failure of organization $i$ is caused by a drop in the value of its underlying assets. This mechanism generates the type of multiple equilibria corresponding to the classical models of self-fulfilling bank runs (e.g. Dybvig and Dybvig, (1983)). The second type of multiple equilibria arises due to interdependencies between organizations: the value of $i$ depends on the value of $j$ and viceverca. There might be two consistent values for $i$ and $j$ : one in which both fail, and another one in which none fail. In this case organizations fail because people expect that other organizations fail, which then becomes self-fulfilling.

3.3. Discussion. It is immediate to observe that the equation (6) has exactly the form of a spatial autoregression, where the relevant weighting matrix is given by the bilateral crossholdings (lending) matrix between countries. Assuming that a natural empirical proxy for the credit riskiness of sovereign's assets is the CDS spread, then $\psi$ captures spillovers in sovereign CDS markets. The model predicts that a sizeable exogenous financial shock reduces assets value i.e. increases riskiness and is empirically reflected in higher CDS spreads. The main message of the theoretical model is that financial networks provide a micro-foundation for contagion in sovereign CDS markets. Therefore, an important contribution of this paper is to provide a precise structural interpretation of this reduced-form econometric approach.

\section{EMPIRICAL FrameWORK}

4.1. Spatial Autoregressions. This section introduces the econometric approach used in this study. The spatial autoregressive model $(\mathrm{SAR})^{5}$ is given by:

$$
y=\rho W y+\beta X+\varepsilon
$$

with data-generating process:

$$
\begin{gathered}
y=\left(\mathbb{I}_{n}-\rho W\right)^{-1}(\beta X+\varepsilon) \\
e \sim N\left(0, \sigma^{2} \mathbb{I}_{n}\right)
\end{gathered}
$$

where $y$ is a vector of CDS spreads, $X$ is a vector of controls and $W$ is a row-normalized spatial weights matrix. $W$ corresponds to a cross-holdings matrix, which gives the consolidated foreign claims of banks from one country on the debt obligations of the general government of another country. All entries on the main diagonal of $W$ are zero to rule out dependence of an observation on its own value.

\footnotetext{
${ }^{5}$ The theoretical model in the previous chapter predicts network (spatial) effects in the dependent variable, which directly translates into a SAR model. Although this is beyond the scope of this paper, if backed by a proper theoretical background, equation (10) could be augmented to include spatial effects in the independent variables, as well as in the error term: $y=\rho W y+\varphi W X+\beta X+\lambda W \varepsilon$. Anselin (2005) suggest running a series of Lagrange Multiplier tests to determine the right specification of spatial interaction: only in the error term (Spatial Error Model) or both in the dependent and independent variables (Spatial Mixed Autoregressive Model).
} 
The spatial parameter $\rho$ measures the magnitude of network spillover effects. It indicates the relevance of a country's network linkages for its probability of default and strongly depends on the particular structure of $W$. The paper tests the following hypotheses:

$$
\begin{aligned}
& H_{0}: \quad \rho=0 \\
& H_{1} \quad: \quad \rho \neq 0
\end{aligned}
$$

Setting $\rho=0$ is tantamount to "switching off" the network, in which case the econometrician is left with a classical linear regression model. The term $W y$ is called a spatial lag and is constructed as a linear combination of neighboring values to each observation. $W y$ is a network risk factor, which reflects the mechanism of transmission of shocks through the financial system.

The presence of spatial lags of the dependent variable renders the OLS parameter estimates and standard errors inconsistent. Fortunately, maximum likelihood is consistent for the spatial autoregressive model in (10) (Lee, 2004).

4.2. Spatial Autoregressions: Parameter Interpretation. When the model contains spatial lags of the dependent variable, interpretation of the parameters becomes more complicated, because the model incorporates a richer information set. In a spatial context, a change in any given explanatory variable (e.g. GDP) will have an impact on the CDS spread of the country itself (direct effect) and potentially an impact of the CDS spreads of other related countries (indirect effect).

To see more clearly the complication of parameter interpretation, rewrite the model in (10) as:

$$
\begin{aligned}
& \left(\mathbb{I}_{n}-\rho W\right) y=\beta X+\varepsilon \\
& y=S(W) X+V(W) \varepsilon
\end{aligned}
$$

where

$$
\begin{gathered}
S(W)=V(W) \mathbb{I}_{n} \beta \\
V(W)=\left(\mathbb{I}_{n}-\rho W\right)^{-1}=\mathbb{I}_{n}+\rho W+\rho^{2} W^{2}+\ldots
\end{gathered}
$$

The infinite series decomposition in (12) demonstrates the nature of spillovers. The shock is transmitted through the system until it diminishes. Powers of $W$ correspond to observations themselves, immediate neighbors (first-order), neighbors of neighbors (second-order) etc. Given $|\rho|<1$, the data-generating process assigns decreasing influence to higher-order neighbors, where the decay declines geometrically as the order increases. If $\rho=0.5$, then $\rho^{2}=0.25, \rho^{3}=$ 0.125 etc. Stronger dependence reflects bigger values for $\rho$, which on its term means that more importance will be assigned to distant neighbors (higher-order).

Following LeSage and Pace (2006), it is possible to define three scalars, which summarize the total, direct and indirect effects:

$i$. Average Direct Impact: the average of the diagonal elements of $S(W)$, which equals $\frac{1}{n} \operatorname{tr}(S(W))$ with $t r$ being the trace of a matrix.

ii. Average Total Impact from an Observation: the sum down the $j$ th column of $S(W)$ gives the impact on all $y$ as a result of changing the credit rating variable by an amount in the $j$ th observation (e.g. Greece's rating going from A to A-). There are $N$ of these sums given by the row vector $r=\iota_{n}{ }^{\prime} S(W)$, where $\iota_{n}{ }^{\prime}$ is a vector of ones. The average of these effects is equal to $\frac{1}{n} r \iota_{n}$.

iii. Average Indirect Effect: the difference between average total impact and average direct impact. 
The response of a country's CDS spread to changes in $X$ is determined by the cross-holdings matrix $W$ through its effect on liquidity provision, the spatial autoregressive parameter $\rho$, which denotes the strength of the network spillover effects, and the parameter $\beta$.

\section{DATA}

5.1. CDS Spreads. CDS spreads offer a hedge against credit risk, in which the protection sellers agrees to compensate the buyer if the underlying defaults before the contract matures. The fee, which the seller charges, is paid up to end of the contract or until the buyer defaults. This fee is denoted as a CDS spread and is usually quoted in basis points. The way CDS contracts are designed makes them a suitable proxy to assess the probability of default of the borrower. Another advantage of CDS spreads is that they are market-based instruments. As such, they are forward-looking and any price changes today reflect anticipated future performance.

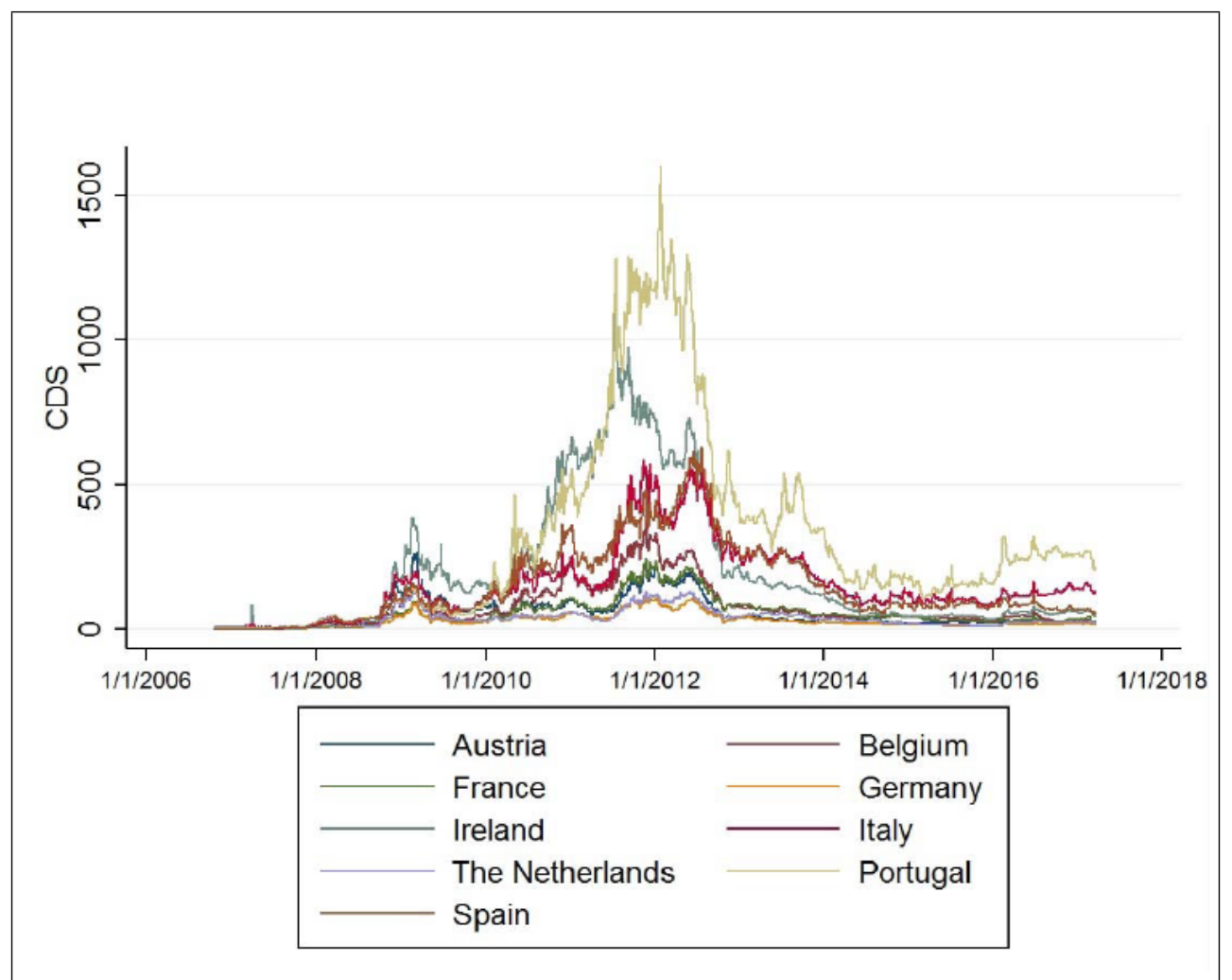

Figure 1: CDS spreads of Euro-zone Countries (The figure plots monthly CDS spreads of 9 Eurozone countries over the period 2007:2017.)

Data for 10 euro-zone sovereigns is collected from Credit Market Analytics (CMA) for the period 2006-2016. The sovereigns included in the sample are: Austria, Belgium, France, Germany, Greece, Ireland, Italy, the Netherlands, Portugal and Spain. All spreads are on 5-year contracts and are used in the analysis either on a monthly or on a daily basis. Since Greek CDS spreads are flat for a large part of the sample (2010-2012), for the main part of the analysis the paper works with 9 countries.

5.2. Financial Linkages. BIS reports consolidated asset holdings of the financial sector vis-àvis entities in other countries at quarterly frequency. This measure includes all financial assets held by the financial sector and offers a breakdown according to the country that issues the claim. This information is contained in Table 9B of the Quarterly BIS Bulletin. A directed link in this network exists if country $i$ holds a claim vis-à-vis country $j$ and the strength of the connection, $x_{i j}$, is given by dollar value of the outstanding debt to country $j$, divided by the 
total amount that country $i$ borrows from all the countries in the sample. The problem is that Table 9B reports all financial claims, not only sovereign debt. On the other hand, Table 4B provides a breakdown on a country level by sector of the counterparty: banks, public sector ${ }^{6}$, non-bank and private sector. According to the definition by BIS, international public sector claims refer to "claims to the general government", which matches the empirical purpose of this paper. Table 4B gives the amount of sovereign debt held abroad, but it does not provide the nationalities of the foreign creditors. I call this amount $D_{i}^{\text {Gvmt }}$. Finally, to obtain the link between two sovereigns I weigh $D_{i}^{\text {Gvmt }}$ by the strength of the connection $x_{i j}$. These weighted directed links are collected in the matrix $W$, which is the main input into the SAR model. Appendix B1 gives an example of how the matrix is constructed.

\section{Empirical Results}

6.1. Summary Statistics. In line with prior empirical evidence, CDS spreads of euro-zone sovereigns exhibit significant degree of co-movement throughout the sample (Figure 2). Prior to the financial crisis, spreads of all countries move closely together. During the peak of the Sovereign Debt Crisis, two groups of countries are noticeable: central countries (France, Germany, Belgium, Austria and the Netherlands) with low CDS spreads and peripheral countries (Portugal, Ireland, Italy and Greece) with high CDS spreads.
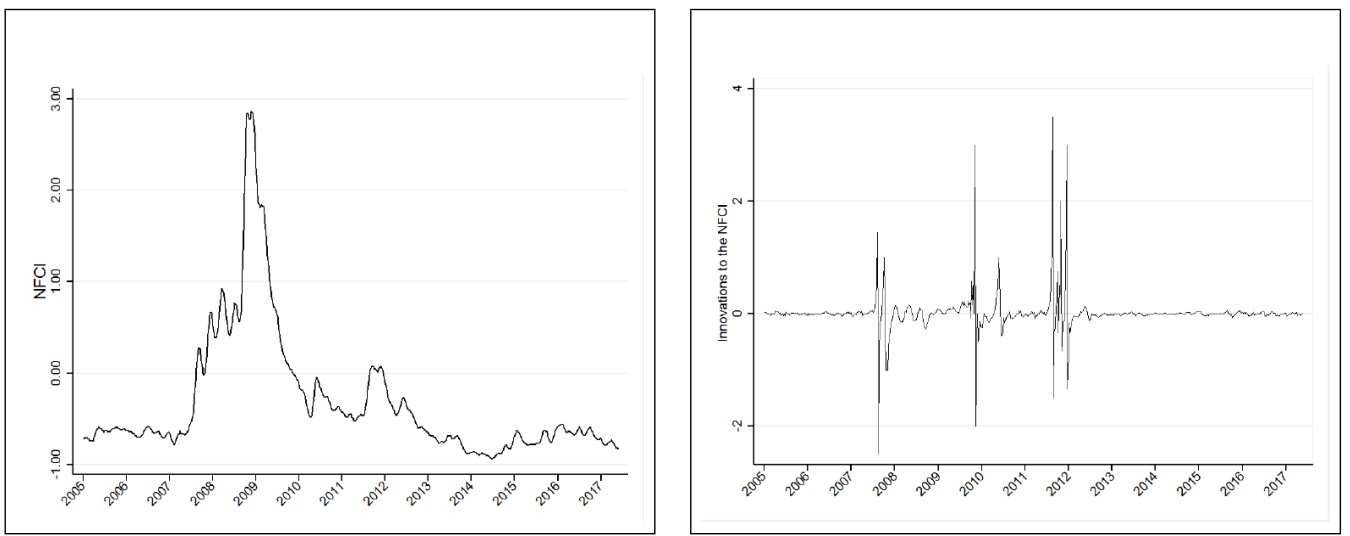

Figure 2: The NFCI Index (The figure plots the NFCI Index: Panel A in levels, Panel B innovations)

Table 1 shows summary statistics of CDS spreads over the sample period from 2006-2016.

\begin{tabular}{|l|c|c|c|c|}
\hline \multicolumn{5}{|c|}{ Table 1: Summary Statistics of CDS Spreads } \\
\hline Country & Mean & Min & Max & SD \\
\hline Austria & 55.81 & 1.4 & 255.81 & 51.90 \\
\hline Belgium & 76.51 & 1.7 & 307.41 & 73.02 \\
\hline France & 57.08 & 1.5 & 214.86 & 49.16 \\
\hline Germany & 30.58 & 1.5 & 114.35 & 25.11 \\
\hline Greece & 10504.24 & 4.5 & 37030.49 & 15899.13 \\
\hline Ireland & 202.50 & 2 & 866.19 & 232.82 \\
\hline Italy & 158.85 & 5.6 & 563.40 & 125.92 \\
\hline The Netherlands & 38.53 & 1.3 & 128.27 & 30.55 \\
\hline Portugal & 304.35 & 3.4 & 1471.74 & 323.74 \\
\hline Spain & 152.34 & 2.5 & 595.93 & 133.00 \\
\hline
\end{tabular}

Countries such as Austria, France, Germany and the Netherlands have mean spreads between 30 and 50 basis points, whereas the spreads of Ireland, Italy, Portugal and Spain exhibit spreads that are on average 5 to 10 times bigger. Germany has the lowest mean and lowest standard

\footnotetext{
${ }^{6}$ In more recent reports the term "public sector" is substituted with the term "official sector".
} 
deviation and is regarded as the risk-free asset in the analysis. In all subsequent sessions, any reference to spreads should be understood to be on an adjusted basis (CDSadj) i.e. the spread over Germany ${ }^{7}$.

6.2. In-sample Results. Table 2 compares the in-sample performance of a standard model of CDS spreads (columns (1)-(2)) and the SAR model (columns (3)-(5)). Spreads in the standard model are specified as a persistent mean-reverting process determined by local factors, driven by fundamentals, and a global factor, driven by risk-aversion. To capture the impact of fundamentals, I use debt-to-GDP ratio (Debt) and deficit-to-GDP ratio (Deficit). Risk aversion is proxied by Moody's Baa-Aaa spread (spread).

\begin{tabular}{|c|c|c|c|c|}
\hline \multicolumn{5}{|c|}{ Table 2: In-sample Regression Analysis } \\
\hline \multicolumn{5}{|c|}{$\triangle C D S_{t}=\beta_{0}+\rho W \Delta C D S_{t}+\beta_{1}$ Debt $_{t}+\beta_{2}$ Deficit $_{t}+$} \\
\hline \multicolumn{5}{|c|}{$+\beta_{3} \operatorname{RiskAv}_{t}+\beta_{4} C D S_{t-1}+\beta_{5} \operatorname{RiskAv}_{t-1}+\varepsilon_{t}$} \\
\hline & OLS Standard & OLS Standard & SAR: & SAR: \\
\hline & Model & Model & $2005 \mathrm{Q} 3$ & 2005Q3 \\
\hline & $(1)$ & $(2)$ & $(3)$ & $(4)$ \\
\hline \multirow[t]{2}{*}{$\rho$} & & & $0.64 * * *$ & $0.61 * * *$ \\
\hline & & & $(28.93)$ & $(25.88)$ \\
\hline \multirow[t]{2}{*}{ Debt } & 0.08 & $0.34^{* * *}$ & 0.035 & $0.111^{* *}$ \\
\hline & $(1.39)$ & $(5.29)$ & $(0.80)$ & $(2.14)$ \\
\hline \multirow[t]{2}{*}{ Deficit } & $-1.18^{* * *}$ & $-1.25^{* * *}$ & $-1.12^{* * *}$ & $-1.32^{* * *}$ \\
\hline & $(-3.49)$ & $(-5.11)$ & $(-4.16)$ & $(-4.58)$ \\
\hline \multirow[t]{2}{*}{$R i s k A v$} & $45.00^{* * *}$ & 6.09 & $19.46^{* * *}$ & 0.40 \\
\hline & $(5.80)$ & $(0.33)$ & $(3.10)$ & $(0.04)$ \\
\hline \multirow[t]{2}{*}{$C D S_{t-1}$} & $-0.11^{* * *}$ & $-0.14^{* * *}$ & $-0.06^{* * *}$ & $-0.06^{* * *}$ \\
\hline & $(-12.80)$ & $(-12.99)$ & $(-8.47)$ & $(-8.75)$ \\
\hline \multirow[t]{2}{*}{ RiskAv $v_{t-1}$} & $-56.16^{* * *}$ & $-32.98 * * *$ & $-23.75^{* * *}$ & $-13.15^{*}$ \\
\hline & $(-7.84)$ & $(-3.66)$ & $(-3.76)$ & $(-1.75)$ \\
\hline \multirow[t]{2}{*}{$G D P$} & & $-0.82^{* * *}$ & & $-0.40^{*}$ \\
\hline & & $(-2.74)$ & & $(-1.64)$ \\
\hline \multirow[t]{2}{*}{$V S T O X X$} & & $1.07 * * *$ & & $0.60 * * *$ \\
\hline & & $(4.07)$ & & $(2.72)$ \\
\hline \multirow[t]{2}{*}{ StockInd } & & 0.000 & & 0.000 \\
\hline & & $(0.33)$ & & $(0.03)$ \\
\hline \multirow[t]{2}{*}{$M R O$} & & $2.47 * * *$ & & 0.84 \\
\hline & & $(4.19)$ & & $(1.58)$ \\
\hline \multirow[t]{2}{*}{ Eonia } & & -3.95 & & -1.55 \\
\hline & & $(-1.44)$ & & $(-0.67)$ \\
\hline \multirow[t]{2}{*}{ Libor - OIS } & & $-2.06^{* * *}$ & & -0.95 \\
\hline & & $(-2.95)$ & & $(-1.55)$ \\
\hline \multirow[t]{2}{*}{ Size FinSector } & & $0.23^{* * *}$ & & $0.20^{* * *}$ \\
\hline & & $(4.75)$ & & $(3.75)$ \\
\hline $\operatorname{Adj} R^{2}, \%$ & 18.64 & 26.42 & 48.70 & 49.50 \\
\hline Observations & 1080 & 1080 & 1080 & 1080 \\
\hline
\end{tabular}

The table reports the results of regressing changes in CDS spreads on innovations of the National Financial Conditions Index (NFCI) published by the Federal Reserve Bank of St. Louis (FRED), a set of controls and a spatial lag (column 3). The sample ranges from 2006 to 2017 . T-stats are reported in parentheses. Significance at the $1 \%, 5 \%$ and $10 \%$ is given by $* * * * *$ and $*$ respectively.

\footnotetext{
${ }^{7}$ p-values based on Augmented Dickey-Fuller (ADF) regressions show that the adjusted measure, CDSadj is stationary.
} 
The results of the OLS regression are consistent with prior findings in the literature: the higher the indebtedness of a sovereign, the higher the CDS spread; the smaller the fiscal deficit, the smaller the CDS spread; the higher the risk aversion and market uncertainty, the higher is the CDS spread. Importantly, the standard model is able to explain around $19 \%$ of the total variation. In column (2), the model adds other controls, which have been found relevant in the empirical literature. These include: GDP, volatility of the stock market (VSTOXX), the ECB's interest rate $(M R O)$, The overnight interbank offered rate (Eonia), the spread LIBOR-OIS and the size of the financial sector (SizeFinSector). It is interesting to note that even though the model is saturated with many variables, the improvement in explanatory power is low.

\begin{tabular}{|c|c|c|c|c|c|}
\hline \multicolumn{6}{|c|}{ Table 3: Decomposition: Direct, Indirect and Total Effects } \\
\hline \multicolumn{6}{|c|}{ (This table reports the decomposition to and indirect effects } \\
\hline & Debt the coefficients of the SAR model in column (3) of Table 2) \\
\hline & Deficit & RiskAv & $\triangle C D S_{t-1}$ & RiskAv $v_{t-1}$ \\
\hline Direct & 0.04 & $-1.28^{* * *}$ & $22.42^{* * *}$ & $-0.06^{* * *}$ & $-27.26^{* * *}$ \\
\hline & $(0.85)$ & $(-4.14)$ & $(3.24)$ & $(-8.34)$ & $(-3.85)$ \\
\hline Indirect & 0.05 & $-1.82^{* * *}$ & $31.605^{* * *}$ & $-0.09^{* * *}$ & $-38.43^{* * *}$ \\
\hline & $(0.84)$ & $(-3.89)$ & $(3.24)$ & $(-6.91)$ & $(-3.85)$ \\
\hline Total & 0.10 & $-3.10^{* * *}$ & $54.02^{* * *}$ & $-0.15^{* * *}$ & $-65.70^{* * *}$ \\
\hline & $(0.85)$ & $(-4.04)$ & $(3.26)$ & $(-7.71)$ & $(-3.90)$ \\
\hline OLS & 0.08 & $-1.18^{* * *}$ & $45.00^{* * *}$ & $-0.11^{* * *}$ & $-56.16^{* * *}$ \\
\hline & $(1.39)$ & $(-3.49)$ & $(5.80)$ & $(-12.80)$ & $(-7.84)$ \\
\hline
\end{tabular}

Column (3) reports the results of the SAR model estimated by maximum likelihood. To address endogeneity issues, the spatial weights matrix $W$ is calculated using data from BIS 2005 Q3, which is entirely pre-determined with respect to the sample. The spatial autoregressive parameter $\rho$ is positive and statistically significant. This is evidence for strong network spillover effects. Importantly, the explanatory power of the model increases more than two times with an R-squared of $49 \%$. Adding controls in column (4) does not affect the significance and magnitude of $\rho$. This suggests that the network factor (i.e. spatial lag) is an important determinant of credit risk, which is omitted from standard specifications. Table 3 shows the decompositions of total effects into direct and indirect effects using the formulae from Section 4.2. Indirect effects constitute approximately $60 \%$ of the overall effect. This means that a substantial proportion of a sovereign's CDS spread reflects the credit riskiness of countries it is connected to in the financial network. Another way to think about this result is that in the counterfactual world, where sovereigns were financially disconnected from one another, CDS spreads would be about $60 \%$ lower.

6.3. Out-of-sample Prediction. The main hypothesis of the paper is that financial linkages among sovereigns contain valuable information, which can be used to predict future CDS spreads. To test this hypothesis, I estimate both the standard and SAR models on monthly data from 2006 to 2012. Data is split into an estimation sample (2006:2010) and an evaluation sample (2011-2012). The evaluation period is chosen deliberately to cover the Sovereign Debt Crisis. The estimation includes the Greek CDS spread in the sample and conditions on the spatial lag, fundamentals and risk aversion. Conditioning on the same set of information allows to attribute differences in forecasting performance to the way the two models process the same information. The evaluation sample consists of Austria, Belgium, France, Ireland, Italy, the Netherlands, Portugal and Spain i.e. Germany and Greece are excluded. Germany is considered to be the safe asset, whereas in the case of Greece the sharp increase in CDS was due to misrepresentation of fundamentals, which means that the Greek spread is unlikely to be predicted from a weighted average of countries in the financial network.

Table 4 reports the results for predicted CDS spreads in changes (Panel A) and in levels (Panel B). The mean observed change in CDS spread is -70.88. The standard model is unable to match the pattern of co-movement in the data with a predicted mean of -6.38 , which is 
nearly 63 basis points away from the observed one. The SAR model predicts -31.83 , which is an improvement of 25.45 basis points. Furthermore, the SAR model improves the forecasting accuracy by $20 \%$ in the root-mean-squared-error (RMSE) sense. Turning to predictions in levels (Panel B), the results are even more impressive. The observed mean CDS spread is 237.60 basis points. The prediction of the standard model, 77.52 basis points, misses the true mean by 160 basis points. The SAR model on the other hand predicts spreads, which at mean value of 159.99 are considerably closer to the true data. In terms of accuracy, the SAR model reduces RMSE by approximately $15 \%$.

\begin{tabular}{|c|c|c|c|}
\hline \multicolumn{4}{|c|}{ Table 4: Predictive Regressions } \\
\hline & Observed Values & Standard Mod & SAR: $2005 \mathrm{Q} 3$ \\
\hline \multicolumn{4}{|c|}{ PanelA : SpreadsChanges $\Delta C D S_{t}$} \\
\hline Mean & $-70.88 * * *$ & $-6.38 * * *$ & $-31.83 * * *$ \\
\hline & $(<0.00)$ & $(<0.00)$ & $(<0.00)$ \\
\hline$S D$ & 72.17 & 9.15 & 84.02 \\
\hline Min & -541.72 & -28.51 & -140.00 \\
\hline $\operatorname{Max}$ & 215.99 & 5.026 & 43.00 \\
\hline$R M S E$ & & 96.11 & 76.47 \\
\hline \multicolumn{4}{|c|}{ PanelB : SpreadsLevel } \\
\hline Mean & 237.60 & $77.52 * * *$ & $159.99 * * *$ \\
\hline & & $(<0.00)$ & $(<0.00)$ \\
\hline$S D$ & 281.45 & 44.40 & 70.36 \\
\hline Min & -9.36 & -18.47 & 18.035 \\
\hline $\operatorname{Max}$ & 1386.55 & 203.14 & 358.45 \\
\hline$R M S E$ & & 295.86 & 253.35 \\
\hline
\end{tabular}

The table reports the results of out-of-sample predictive performance of the standard model and the SAR model during the period 2011 to 2012. Parameters have been estimated using data from 2006:2010. The standard model and SAR model simulations are conditioned to the same information set consisting of the behavior of the Greek CDS spread, fiscal fundamentals in all euro area countries and the Baa-Aaa spread. The weight matrix used in the SAR model is constructed using BIS data from 2005 Q3. p-values are reported in parentheses. Significance at the $1 \%, 5 \%$ and $10 \%$ is given by ***, ** and * respectively

The SAR model consistently outperforms the standard model both in terms of matched values and accuracy. The SAR model with a spatial weights matrix based on sovereign financial linkages offers a powerful, yet intuitive tool for modeling and forecasting of CDS spreads. Incorporating network connections into the analysis is an econometrically challenging task, because it involves the joint estimation of a large number of parameters. Modelling $N$ countries requires estimating $N^{2}-N$ dependence relations. The SAR model overcomes the problem by imposing a parsimonious structure, whereby network spillovers are summarized by means of a single parameter. Another point worth discussing here is that financial networks are typically slowly evolving. This is of great practical relevance given the high explanatory power of the network factor. A policy maker or an investor, who has a snapshot of the network this quarter will have a reasonably good understanding of how the network will look like in the next two to four quarters. This makes the SAR model a useful tool for risk management and stress testing.

6.4. Shocks Transmission. The results of the paper indicate that the network of financial exposures is an important systematic factor driving sovereign CDS spreads. The network transmits and amplifies shocks across the financial market, which affects the solvency of each entity in the financial system and, consequently its CDS spread. For example, during the financial crisis in 2008 a problem originating in the US subprime mortgage market quickly spread and infected the global financial system. It is interesting to see to what extent financial events transmit through the sovereign financial network.

To identify exogenous financial shocks, I use data on the National Financial Conditions Index (NFCI), which is published by the Federal Reserve Bank of Chicago. This index provides a comprehensive weekly update on US financial conditions in money markets, debt markets, 
equity markets and the traditional and "shadow" banking systems. The NFCI is published every week at 08:30 a.m. ET on Wednesday and reflects information for the time period through Friday. To construct financial shocks, innovations of the NFCI are taken and values between announcement days are linearly interpolated (ShockNFCI). High values of the NFCI signify economic instability, whereas low values indicate downturn and recession. The mean value of the index is -0.33 , the minimum is -0.94 and the maximum is 2.86 . The average value of the innovations is 0.001 with occasional positive spikes (positive shocks) and negative spikes (negative shocks).

\begin{tabular}{|c|c|c|c|}
\hline \multicolumn{4}{|c|}{$\begin{array}{l}\text { Table 5: Response of CDS Spreads to Exogenous Financial Shocks } \\
\qquad \text { CDS } S_{t}=\beta_{0}+\rho W \Delta C D S_{t}+\beta_{1} \text { FinShock }_{t}+\beta_{2} \text { Debt }_{t}+ \\
+\beta_{3} \text { Deficit } t+\beta_{4} \text { Spread }_{t}+\beta_{5} \Delta C D S_{t-\grave{a} \grave{a}}+\beta_{6} \text { Spread }_{t-1}+\varepsilon_{t}\end{array}$} \\
\hline & OLS No Spatial Lag & SAR: 2005Q3 & SAR: Average \\
\hline & $(1)$ & $(2)$ & $(3)$ \\
\hline \multicolumn{4}{|c|}{ PanelA : PointEstimates } \\
\hline \multirow[t]{2}{*}{$\rho$} & & $0.49^{* * *}$ & $0.40^{* * *}$ \\
\hline & & $(77.58)$ & $(54.08)$ \\
\hline \multirow[t]{2}{*}{ ShockNFCI } & $15.37^{* * *}$ & $8.40^{* * *}$ & $9.15^{* * *}$ \\
\hline & $(3.80)$ & $(2.28)$ & $(2.43)$ \\
\hline \multirow[t]{2}{*}{ Debt } & 0.32 & 0.75 & 0.72 \\
\hline & $(0.115)$ & $(0.37)$ & $(0.34)$ \\
\hline \multirow[t]{2}{*}{ Deficit } & $-0.067^{* * *}$ & $-0.067^{* * *}$ & $-0.06^{* * *}$ \\
\hline & $(-4.72)$ & $(-4.75)$ & $(-4.39)$ \\
\hline \multirow[t]{2}{*}{ Spread } & -0.89 & -0.16 & -0.48 \\
\hline & $(-0.44)$ & $(-0.08)$ & $(-0.25)$ \\
\hline \multirow[t]{2}{*}{$\Delta C D S_{t-1}$} & $-0.002^{* * *}$ & $-0.002^{* * *}$ & $-0.002^{* * *}$ \\
\hline & $(-5.87)$ & $(-4.85)$ & $(-5.57)$ \\
\hline \multirow[t]{2}{*}{ Spread $_{t-1}$} & 0.88 & 0.14 & 0.47 \\
\hline & $(0.43)$ & $(0.07)$ & $(0.25)$ \\
\hline \multirow[t]{2}{*}{ Constant } & -0.026 & -0.032 & -0.038 \\
\hline & $(-0.17)$ & $(-0.25)$ & $(-0.26)$ \\
\hline $\operatorname{Adj} R^{2}, \%$ & 00.25 & 17.16 & 14.02 \\
\hline Observations & 23490 & 23490 & 23490 \\
\hline \multicolumn{4}{|c|}{ PanelB : DecompositionofFinShock } \\
\hline \multirow[t]{2}{*}{ DirectEffect } & & $8.95^{* * *}$ & $9.49^{* * *}$ \\
\hline & & $(2.25)$ & $(2.45)$ \\
\hline \multirow[t]{2}{*}{ IndirectEf fect } & & $7.73^{* * *}$ & $5.80^{* * *}$ \\
\hline & & $(2.24)$ & $(2.45)$ \\
\hline \multirow[t]{2}{*}{ TotalEffect } & $15.37 * * *$ & $16.68^{* * *}$ & $15.30^{* * *}$ \\
\hline & $(3.23)$ & $(2.24)$ & $(2.45)$ \\
\hline
\end{tabular}

The table reports the results of regressing changes in CDS spreads on innovations of the National Financial Conditions Index (NFCI) published by the Federal Reserve Bank of St. Louis (FRED), a set of controls and a spatial lag (column 3). The sample ranges from 2006 to 2017 . T-stats are reported in parentheses. Significance at the $1 \%, 5 \%$ and $10 \%$ is given by ***, ** and * respectively.

Panel A of Table 5 shows that CDS spreads react significantly to unexpected changes in the NFCI index. In terms of point estimates, a 100 bps increase in the index increases spreads by between 15 to 16 bps. Importantly, nearly $45 \%$ of the total market reaction is due to indirect network effects (Panel B). The role of the network is to amplify the exposure to the common financial shock. Another way to look at this result is to say that in the counterfactual world, in which the financial network did not exist, the reaction of sovereign CDS spreads would be $45 \%$ lower. 


\section{Robustness}

7.1. Time-varying spatial dependence. The presence of network spillovers in CDS markets could be an artefact of the long sample or it could be driven by very strong spillovers during a sub-sample of the data. Therefore, it is useful to see how the magnitude of network effects evolves over time. Table 6 presents the results for five sub-samples. The value of $\rho$ is lowest during 2006:2007, when CDS spreads are low and the levels of risk are small. It skyrockets during 2008:2010 to 0.67 at the peak of the Liquidity Crisis and the onset of the Sovereign Debt Crisis. During 2011:2012, the value of the parameter is reduced nearly in half, which is a result of government interventions and macroeconomic policies aiming at decoupling the financial system. During the next two periods after the crisis, values of the parameter increase, which reflects the strong co-movement and narrowing down of the differences in CDS spreads between countries in the sample. These results are consistent with the graphical evidence in Figure 2.

\begin{tabular}{|c|c|c|c|c|c|}
\hline \multicolumn{7}{|c|}{ Table 6: SAR Model: Sub-samples } \\
\hline & $2006: 2007$ & $2008: 2010$ & $2011: 2012$ & $2013: 2014$ & $2015: 206$ \\
\hline & $(1)$ & $(2)$ & $(3)$ & $(4)$ & $(5)$ \\
\hline & $0.25^{* *}$ & $0.67^{* * *}$ & $0.38^{* * *}$ & $0.52^{* * *}$ & $0.46^{* * *}$ \\
\hline & $(2.08)$ & $(18.11)$ & $(4.07)$ & $(13.46)$ & $(6.39)$ \\
\hline Debt & -0.3 & 0.026 & 0.17 & 0.06 & $0.09^{*}$ \\
\hline & $(-0.46)$ & $(0.42)$ & $(0.69)$ & $(0.94)$ & $(1.71)$ \\
\hline Deficit & -0.002 & $-1.08^{* * *}$ & -1.83 & -0.22 & -0.006 \\
\hline & $(-0.02)$ & $(-4.27)$ & $(-1.09)$ & $(-0.54)$ & $(-0.01)$ \\
\hline RiskAv & 3.42 & $16.93^{* * *}$ & 43.25 & 14.68 & 4.43 \\
\hline & $(1.40)$ & $(3.34)$ & $(1.05)$ & $(0.72)$ & $(0.49)$ \\
\hline CDS $S_{t-1}$ & $-0.18^{* * *}$ & -0.003 & $-0.04^{* *}$ & $-0.06^{* * *}$ & -0.02 \\
\hline & $(-2.96)$ & $(-0.14)$ & $(-1.99)$ & $(-5.69)$ & $(-1.02)$ \\
\hline RiskAv $t-1$ & 6.33 & $-21.11^{* * *}$ & $-132.32^{* * *}$ & -9.97 & 1.79 \\
\hline & $(1.39)$ & $(-4.02)$ & $(-3.01)$ & $(-0.42)$ & $(0.19)$ \\
\hline AdjR $R^{2}, \%$ & 17.49 & 54.04 & 29.98 & 41.85 & 18.38 \\
\hline Observations & 117 & 327 & 216 & 216 & 207 \\
\hline
\end{tabular}

The table reports the results of regressing changes in CDS spreads on a spatial lag and a set of controls over four sub-samples of the data. The full sample ranges from 2006 to 2017 . T-stats are reported in parentheses. Significance at the $1 \%, 5 \%$ and $10 \%$ is given by $* * *, * *$ and $*$ respectively.

7.2. Out-of-sample Prediction. One of the main results of the paper is that the SAR model predicts well in out-of-sample tests related to the Sovereign Debt Crisis of 2013/2014. Given the result of the previous section, which shows that the magnitude of network effects varies over time, it becomes imperative to investigate whether the predictive ability of the model holds in normal, as well as crisis times. I test this by estimating the model on monthly data from January 2013 to December 2014 and evaluating it on data from 2015 to 2016. I condition on fundamentals, spreads (Baa-Aaa) and the spatial lag and perform the analysis in both levels and in CDS changes. Table 7 shows that both models work better in normal times than in crisis periods. However, what is more important is that the SAR model significantly outperforms the standard model, both in its ability to better match the true mean and in terms of RMSE. Actually, RMSE for the SAR model is nearly 3 times smaller than the RMSE of the standard model. Furthermore, the results hold for all sub-sample periods used in Table 6 but are not tabulated here to preserve space.

7.3. Alternative Specifications of the Spatial Weights Matrix. To address robustness of the special weights matrix, I compute 4 alternative weighting schemes and present the results in Table 7. First, I use a categorical spatial matrix, computed in the following way. Data for 
financial linkages is averaged over all periods from 2006 Q1 to 2016 Q4 and collected in a matrix Average. Then the following rule is applied:

$$
w_{i j}\left\{\begin{array}{cr}
1 & \text { if } \text { average }_{i j} \leq p .25 \\
2 & \text { if p.25 }<\text { average }_{i j} \leq p .50 \\
3 & \text { if average } \\
i j & \geq p .75
\end{array}\right.
$$

where $p .25, p .50$ and $p .75$ stand for the 25 th, 50 th and 75 th percentile of the matrix Average. The spatial autoregressive parameter is still statistically significant, but its magnitude is reduced because the categorical weighting matrix discards some information.

\begin{tabular}{|c|c|c|c|}
\hline \multicolumn{4}{|c|}{ Table 7: Other Predictive Regressions } \\
\hline & ObservedValues & StandardModel & $S A R: 2005 Q 3$ \\
\hline \multicolumn{4}{|c|}{ PanelA : SpreadsChanges $\Delta C D S_{t}$} \\
\hline Mean & $-15.32 * * *$ & $21.41 * * *$ & $-5.45 * *$ \\
\hline & $(<0.00)$ & $(<0.00)$ & $(<0.00)$ \\
\hline$S D$ & 10.72 & 8.73 & 5.00 \\
\hline Min & -66.13 & 7.36 & -17.34 \\
\hline $\operatorname{Max}$ & 41.52 & 42.96 & 9.76 \\
\hline$R M S E$ & & 38.73 & 13.92 \\
\hline \multicolumn{4}{|c|}{ PanelB : SpreadsLevels } \\
\hline Mean & 48.30 & $-0.61 * * *$ & $9.51 * * *$ \\
\hline & & $(<0.00)$ & $(<0.00)$ \\
\hline$S D$ & 59.01 & 4.45 & 5.58 \\
\hline Min & 0.00 & -9.04 & -1.411 \\
\hline $\operatorname{Max}$ & 279.98 & 11.18 & 24.23 \\
\hline$R M S E$ & & 75.45 & 68.75 \\
\hline
\end{tabular}

The table reports the results of out-of-sample predictive performance of the standard model and the SAR model during the period 2014 to 2015. Parameters have been estimated using data from 2013:2014. The standard model and SAR model simulations are conditioned to the same information set consisting of fiscal fundamentals in all euro area countries and the Baa-Aaa spread. The weight matrix used in the SAR model is constructed using BIS data from 2005 Q3. p-values are reported in parentheses. Significance at the $1 \%, 5 \%$ and $10 \%$ is given by $* * * * *$ and $*$ respectively.

Second, to capture changes in the dynamics of cross-border borrowing and lending I use data from BIS 2010 Q4. Results are largely unaffected, which is due to the persistence of cross-border claims.

The model assumes a closed system i.e. there is no lending and borrowing outside of the network of countries in the sample. However, since in reality countries hold claims vis-à-vis countries outside of the euro-zone, one concern could be that the weighting scheme overstates the true effect. To check whether this is true, I introduce the quantity:

$$
x_{i j}^{B I S}=\frac{a_{i j}}{\sum_{j=1}^{B I S} \sum_{j} a_{i j}}
$$

where $B I S$ stands for the total number of BIS-reporting banks. Using the weighting matrix $W^{B I S}=x_{i j}^{B I S} D_{i}^{\text {Gvmnt }}$ in column (3) alleviates the concern: the sign and magnitude of all coefficients remain close to the baseline specification.

Finally, it is possible that the model mechanically assigns a high value for $\rho$, because CDS spreads are regressed on a weighted average of CDS spreads. In column (4) I use a random pseudo $W$, whose entries are drawn from an uniform distribution. The value of $\rho$ is 0.13 , which is 5 times lower than the values in the baseline estimate. These results indicate that the large network effects are due to the specific structure of the financial netwowk and are not driven by randomness. 


\begin{tabular}{|c|c|c|c|c|}
\hline \multicolumn{5}{|c|}{ Table 8: Robustness Results for the Spatial Weights Matrix } \\
\hline \multicolumn{4}{|c|}{ (The Table reports robustness checks using different spatial weight matrices. } \\
\hline \multicolumn{4}{|c|}{ See the text for details on how the matrices $(1)-(4)$ are constructed.) } \\
\hline & $(1)$ & $(2)$ & $(3)$ & $(4)$ \\
\hline & $0.44^{* * *}$ & $0.59^{* * *}$ & $0.62^{* * *}$ & $0.13^{* * *}$ \\
\hline & $(16.20)$ & $(27.03)$ & $(29.28)$ & $(18.09)$ \\
\hline & $1.10^{* *}$ & 0.03 & 0.04 & $0.124^{* *}$ \\
\hline Debt & $(2.28)$ & $(0.81)$ & $(0.88)$ & $(2.26)$ \\
\hline Deficit & $-1.08^{* * *}$ & $-1.07^{* * *}$ & $-1.12^{* * *}$ & $-1.42^{* * *}$ \\
\hline & $(-3.61)$ & $(-3.95)$ & $(-4.14)$ & $(-4.67)$ \\
\hline RiskAv & $25.09^{* * *}$ & $20.02^{* * *}$ & $16.83^{* * *}$ & 2.78 \\
\hline & $(3.69)$ & $(3.15)$ & $(2.67)$ & $(0.289)$ \\
\hline CD $S_{t-1}$ & $-0.09^{* * *}$ & $-0.05^{* * *}$ & $-0.06^{* * *}$ & $-0.06^{* * *}$ \\
\hline & $(-12.23)$ & $(-8.29)$ & $(-8.73)$ & $(-8.67)$ \\
\hline RiskA $v_{t-1}$ & $-31.02^{* * *}$ & $-24.52^{* * *}$ & $-21.24^{* * *}$ & $-15.46^{* *}$ \\
\hline & $(-4.53)$ & $(-3.84)$ & $(-3.36)$ & $(-1.96)$ \\
\hline AdjR ${ }^{2}, \%$ & 39.93 & 47.62 & 47.83 & 44.52 \\
\hline Observations & 1080 & 1080 & 1080 & 1080 \\
\hline
\end{tabular}

\section{Conclusion}

To summarize, using a simple network model of sovereign credit risk, this paper provides an economic motivation for the use of spatial autoregressions to model and predict sovereign CDS spreads. In the spirit of recent theoretical work on networks, this paper develops a network model with asset interdependencies. A "balance sheet" mechanism of contagion is considered, where spillovers following an exogenous financial shock (e.g. a US financial shock) occur via direct losses to assets held by creditors. Using a fixed-point argument, it is possible to show that in the presence of asset interdependencies and discontinuities in value multiple equilibrium solutions for organization's values are possible. In this context of multiple equilibria, contagion emerges because of linkages and the joint determination of asset prices: organizations fail because people expect that other connected organizations will fail as well and this then becomes self-fulfilling.

Using methods from spatial econometrics, the paper makes two empirical findings. First, the paper shows that the constructed network of financial linkages between sovereigns is an important mechanism for the propagation of exogenous financial shocks. Using the SAR model, it is possible to decompose the total effect of financial shocks to direct and indirect effects. The paper finds that as much as $45 \%$ of the overall effect of shocks is due to indirect (network) effects. Second, in out-of-sample predictive tests, the SAR model consistently outperforms standard models. The SAR model is better able to match monthly changes in CDS spreads and leads to $15 \%$ to $20 \%$ improvement in predictive accuracy.

This paper opens several avenues for future research. To understand better how financial networks between sovereigns affect markets, it is important to study whether and to what extent other type of shocks transmit through the financial network of sovereigns. For example, it could be inte resting to test the transmission of country-specific shocks to fundamentals or common macroeconomic shocks, such as monetary policy shocks.

\section{REFERENCES}

[1] Acemoglu, D., Ozdaglar, A., \& Tahbaz-Salehi, A. (2015). Systemic Risk and Stability in Financial Networks. American Economic Review, 105, 564-608.

[2] Allen, F., \& Gale, D. (2000). Financial contagion. Journal of Political Economy, 108, 1-33.

[3] Allen, F., Babus, A., \& Carletti, E. (2010). Financial connections and systemic risk. National Bureau of Economic Research. 
[4] Amato, D., \& Remolona, E. (2003). The credit spread puzzle. BIS Quarterly Bulletin, 51-63.

[5] Anselin, L., \& Bera, A. (1998). Spatial dependence in linear regression models with an introduction to spatial econometrics. Statistics Textbooks and Monographs, 155, 237-290.

[6] Arbia, G. (2006). Spatial econometrics: statistical foundations and applications to regional convergence. Berlin, Heidelberg: Springer Science and Business Media.

[7] Attinasi, M., Checherita, C., \& Nickel, C. (2010). What explains the surge in euro area sovereign spreads during the Financial Crisis 2007-2009? Public Finance and Management, 10(4), 595-645.

[8] Barucca, P., Bardosia, M., Caccioli, F., D'Errico, M., Visentin, G., Battiston, S., \& Caldarelli, G. (2020). Network Valuation in Financial Systems. Mathematical Finance, 30(4), 1181-1204.

[9] Battiston, S., Gatti, D., Gallegatti, M., Greenwald, B., \& Stiglitz, J. (2012). Liaisons dangereuses: Increasing connectivity, risk sharing, and systemic risk. Journal of Economic Dynamics and Control, 36(8), 1121-1141.

[10] Beber, A., Brandt, M., \& Kavajecz, K. (2009). Flight-to-quality or flight-to-liquidity? Review of Financial Studies, 22(3), 925-957.

[11] Blasques, F., Koopman, S., Lucas, A., \& Schaumburg, J. (2016). Spillover dynamics for systemic risk measurement using spatial financial time series models. Journal of Econometrics, 195(2), 211-223.

[12] Bloningen, B., Davies, R., Waddell, G., \& Naughton, T. (2007). FDI in space: Spatial autoregressive relationships in foreign direct investment. European Economic Review, 51(5), 1303-1325.

[13] Bonaldi, P., Hortacsu, A., \& Kastl, J. (2014). An empirical analysis of systemic risk in the euro-zone. Manuscript, Stanford University. Online from https://www.nber.org/papers/w21462.

[14] Bordignon, M., Cerniglia, F., \& Revelli, F. (2003). In search of yardstick competition: a spatial analysis of Italian municipality property tax setting. Journal of Urban Economics, 54(2), 199-217.

[15] Chen, L., Collin-Dufresne, P., \& Goldstein, R. (2008). On the relation between the credit spread puzzle and the equity premium puzzle. The Review of Financial Studies, 22(9), 3367-409.

[16] Codogno, L., Favero, C., \& Missale, A. (2003). Yield spreads on EMU government yields. Economic Policy, 18(37), 503-532.

[17] Diebold, F., \& Yilmaz, K. (2009). Measuring financial asset return and volatility spillovers, with application to global equity markets. Economic Journal, 119, 158-171.

[18] Diebold, F., \& Yilmaz, K. (2011). Equity market spillovers in Americas. (R. Alfaro, editor) Financial Stability, Monetary Policy and Central Banking, 199-214.

[19] Dybvig, D., \& Dybvig, P. (1983). Bank runs, Deposit Insurance and Liquidity. Journal of Political Economy, 91, 401-419.

[20] Eder, A., \& Keiler, S. (2015). CDS Spreads and Contagion Amongst Systemically Important Financial Institutions-A Spatial Econometric Approach. International Journal of Finance \& Economics, 20(4), 291309.

[21] Eisenberg, L., \& Noe, T. (2001). Systemic Risk in Financial Systems. Management Science, 47, $236-249$.

[22] Elliot, M., Golub, B., \& Jackson, M. (2014). Financial Networks and Contagion. American Economic Review, 104(10), 3115-3153.

[23] Favero, C. (2013). Modeling and forecasting government bond spreads in the euro area: a GVAR model. Journal of Econometrics, 177(2), 343-356.

[24] Favero, C., Pagano, M., \& von Thadden, E.-L. (2010). How does liquidity affect government bond yields? Journal of Financial and Quantative Analysis, 45(1), 107-134.

[25] Fernandez, V. (2011). Spatial linkages in international financial markets. Quantative Finance, 11(2), 237245.

[26] Freixas, X., Parigi, B., \& Rochet, J. (2000). Systemic risk, interbank relations and liquidity provision by the central bank. Journal of Money, Credit and Banking, 32(3), 611-638.

[27] Gai, P., Hadane, A., \& Kapadia, S. (2011). Complexity, concentration and contagion. Journal of Monetary Economics, 58(5), 453-470.

[28] Gande, A., \& Parsley, D. (2005). News spillovers in the sovereign debt market. Journal of Financial Economics, 75(3), 691-734.

[29] Geier, A., Kossmeier, S., \& Pichler, S. (2004). Measuring systematic risk in EMU government yield spreads. Review of Finance, 8(2), 171-197.

[30] Georg, C. (2013). The effect of the interbank network structure on contagion and common shocks. Journal of Banking and Finance, 37(7), 2216-2228.

[31] Glasserman, P., \& Young, H. (2015). How likely is contagion in financial networks? Journal of Banking and Finance, 50, 383-399.

[32] Glover, B., \& Richards-Shubik, S. (2016). Contagion in the European Sovereign Debt Crisis. Working Paper. Online from https://www.nber.org/papers/w20567, accessed 1 Sept,2017.

[33] Kelejian, H., \& Prucha, I. (1998). A generalized spatial two-stage least squares procedure for estimating a spatial autoregressive model with autoregressive disturbances. The Journal of Real Estate Finance and Economics, 17(1), 99-121. 
[34] Kim, C., Phipps, T., \& Anselin, L. (2003). Measuring the Benefits of Air Quality Improvement: A Spatial Hedonic Appriach. Journal of Environmental Economics and Management, 45, 24-39.

[35] Laubach, T. (2009). New Evidence on the interest rate effect of budget deficits and debt. Journal of the European Economic Association, 7(4), 858-885.

[36] Laubach, T. (2011). Fiscal policy and interest rates: the role of sovereign default risk. NBER International Seminar on Macroeconomics, 7(1), 7-30.

[37] Le Gallo, J., Ertur, C., \& Baumont, C. (2003). A spatial econometric analysis of convergence across European regions, 1980-1995. (B.Fingleton, editor). European Regional Growth.Advances in Spatial Science. Berlin,Heidelberg: Springer.

[38] Lee, L.-F. (2004). Asymptotic Distributions of Quasi-Maximum Likelihood Estimators for Spatial Econometric Models. Econometrica, 72, 1899-1926.

[39] Leitner, Y. (2005). Financial networks: Contagion, commitment, and private sector bailouts. Journal of Finance, 60(6), 2925-2953.

[40] LeSage, J., \& Page, R. (2009). Introduction to Spatial Econometrics. CRC Press Taylor \& Francis.

[41] Longstaff, F., Pan, J., Pedersen, L., \& Singleton, K. (2011). How sovereign is sovereign credit risk? American Economic Journal, 3(2), 75-103.

[42] Nier, E., Yang, J., Yorulmazer, T., \& Alenton, A. (2007). Network models and financial stability. Journal of Economic Dynamics, 31(6), 2033-2060.

[43] Peseran, M., Schuermann, T., \& Weiner, S. (2004). Modeling Regional Interdependencies using a Global Error-correcting macroeconometric Model. Journal of Business and Economic Statistics, 22(2), 129-162.

[44] Rogers, L., \& Veraart, L. (2013). Failure and rescue in the interbank network. Management Science, 59, 882-898.

[45] Suzuki, T. (2002). Valuing corporate debt: the effect of cross-holdings of stock and debt. Journal of the Operations Research Society, 45, 123-144.

[46] Weber, M., \& Ozdagli, A. (2016). Monetary Policy through Production Networks. NBER Working Paper 23424. Online from https://www.nber.org/papers/w23424, accessed 23 July 2017. 


\section{List of Figures}

Figure 1: CDS spreads of Euro-zone Countries

The figure plots monthly CDS spreads of 9 Eurozone countries over the period 2007:2017.

Figure 2: The NFCI Index

The figure plots the NFCI Index: Panel A in levels, Panel B innovations

\section{List of Tables}

Table 1: Summary Statistics of CDS Spreads

The table gives summary statistics of sovereign CDS spreads.

Table 2: In-sample Regression Analysis

The table reports the results of regressing changes in CDS spreads on innovations of the National Financial Conditions Index (NFCI) published by the Federal Reserve Bank of St. Louis (FRED), a set of controls and a spatial lag (column 3). The sample ranges from 2006 to 2017. T-stats are reported in parentheses. Significance at the $1 \%, 5 \%$ and $10 \%$ is given by ***, ** and * respectively.

Table 3: Decomposition: Direct, Indirect and Total Effects

This table reports the decomposition to and indirect effects of the coefficients of the SAR model in column (3) of Table 2.

Table 4: Predictive Regressions

The table reports the results of out-of-sample predictive performance of the standard model and the SAR model during the period 2011 to 2012. Parameters have been estimated using data from 2006:2010. The standard model and SAR model simulations are conditioned to the same information set consisting of the behavior of the Greek CDS spread, fiscal fundamentals in all euro area countries and the Baa-Aaa spread. The weight matrix used in the SAR model is constructed using BIS data from 2005 Q3. p-values are reported in parentheses. Significance at the $1 \%, 5 \%$ and $10 \%$ is given by $* * *,{ }^{* *}$ and $*$ respectively

Table 5: Response of CDS Spreads to Exogenous Financial Shocks

The table reports the results of regressing changes in CDS spreads on innovations of the National Financial Conditions Index (NFCI) published by the Federal Reserve Bank of St. Louis (FRED), a set of controls and a spatial lag (column 3). The sample ranges from 2006 to 2017. T-stats are reported in parentheses. Significance at the $1 \%, 5 \%$ and $10 \%$ is given by ***, $* *$ and ${ }^{*}$ respectively.

Table 6: SAR Model: Sub-samples

The table reports the results of regressing changes in CDS spreads on a spatial lag and a set of controls over four sub-samples of the data. The full sample ranges from 2006 to 2017. T-stats are reported in parentheses. Significance at the $1 \%, 5 \%$ and $10 \%$ is given by ***,** and $*$ respectively.

Table 7: Other Predictive Regressions

The table reports the results of out-of-sample predictive performance of the standard model and the SAR model during the period 2014 to 2015. Parameters have been estimated using data from 2013:2014. The standard model and SAR model simulations are conditioned to the same information set consisting of fiscal fundamentals in all euro area countries and the Baa-Aaa spread. The weight matrix used in the SAR model is constructed using BIS data from 2005 Q3. p-values are reported in parentheses. Significance at the $1 \%, 5 \%$ and $10 \%$ is given by ***, ** and ${ }^{*}$ respectively.

Table 8: Robustness Results for the Spatial Weights Matrix

The Table reports robustness checks using different spatial weight matrices. See the text for details on how the matrices (1)-(4) are constructed. 